\title{
Review
}

\section{EEG Changes Related to Gut Dysbiosis in Diabetes-Review}

\author{
Roxana Toderean ${ }^{1, *(\mathbb{D}}$, Mihai Dimian ${ }^{2} \mathbb{D}$ and Claudiu Cobuz ${ }^{3,4}$ \\ 1 Institute of Advanced Studies, Stefan cel Mare University of Suceava, 720229 Suceava, Romania \\ 2 Department of Computers, Electronics and Automation, Stefan cel Mare University of Suceava, \\ 720229 Suceava, Romania; dimian@usm.ro \\ 3 Faculty of Medicine and Biological Sciences, Stefan cel Mare University of Suceava, 720229 Suceava, Romania; \\ claudiu.cobuz@usm.ro \\ 4 Department of Diabetes, Nutrition and Metabolic Diseases, Sfântul Ioan cel Nou Emergency Hospital \\ of Suceava, 720224 Suceava, Romania \\ * Correspondence: roxana.toderean@usm.ro
}

check for

updates

Citation: Toderean, R.; Dimian, M. Cobuz, C. EEG Changes Related to Gut Dysbiosis in Diabetes-Review. Appl. Sci. 2021, 11, 11871. https:// doi.org/10.3390/app112411871

Academic Editor: Giovanna Traina

Received: 19 November 2021

Accepted: 9 December 2021

Published: 14 December 2021

Publisher's Note: MDPI stays neutral with regard to jurisdictional claims in published maps and institutional affiliations.

Copyright: (C) 2021 by the authors Licensee MDPI, Basel, Switzerland. This article is an open access article distributed under the terms and conditions of the Creative Commons Attribution (CC BY) license (https:/ / creativecommons.org/licenses/by/ $4.0 /)$.

\begin{abstract}
Humans are facing a devastating epidemic of metabolic syndrome that is linked to the worldwide dramatic increase in obesity and diabetes. Significant evidence suggests that the intestinal microbiota plays a major role in the pathogenesis of metabolic diseases. Due to the gut-brain axis link, dysbiosis in the gut microbiota have been demonstrated in both metabolic and neurological disease. Increasing evidence suggests that the gut microbiota is very important in maintaining health and changes in its composition may contribute to psychiatric and neurodegenerative disorders. It is also in research that changes in microbiota composition profile due to diabetes are modulated by the vagus nerve. Therefore, it is plausible that disruptions in the gut microbiota may be captured through electroencephalography signaling. Several studies which used standard methods of signal processing have highlighted some changes in electroencephalographic rhythms on patients with diabetes.
\end{abstract}

Keywords: microbiota; gut-brain axis; diabetes; electroencephalography; dysbiosis

\section{Introduction}

What causes disease? Traditionally first thought of this question is the genes and then the choices people do in life and what they eat-the lifestyle and what they became exposed to in the environment. In the middle of all these and contributing to their interpretation are the gut microbes, which are a direct link to the genetic material and can influence the body reactions and responses to the environment.

Our body contains about 10 trillion cells and 10 times that number of bacteria. Of all DNA from our body, more than $90 \%$ of them is bacterial DNA, so humans are carrying around a lot of DNA but very little it is actually their own. The microbiome is very important, and it is very well known that the animals kept germ-free are compromised. The animal life may end very quickly in a contact to a pathogen since they have no protection, no immunity. Therefore, the microbiota and microbes studies are very important [1-3].

The human intestinal tract contains a unique group of microorganisms that shape a new organ of the body, known as the gut microbiota, with a weight of more than $1.5 \mathrm{~kg}$ and with ten times more microbial cells than our human eukaryotic cells [4]. While previous studies have mainly focused on the gut microbiota roles on the digestion of complex carbohydrates for the development of innate and adaptive immunity, recent evidence suggests that microbiota also may play key roles in regulating metabolic pathways in health but also in various diseases [5]. More importantly, increasing number of studies show that changes in microbiota composition (dysbiosis) has been associated with chronic disorders including obesity [6,7] diabetes [8,9], inflammatory bowel disease (IBD) [10,11], malnutrition [12], cancer [13], psychiatric and neurodegenerative disorders [14,15].

Claude Bernard, William James, Ivan Pavlov and Walter Cannon, the pioneers of modern physiology, have all described the interrelation between the gut and the brain and 
its importance in maintaining homeostasis [16]. Many other scientific results have emphasized the close connection between the gut in the brain. For example, in brain dead people, the stomach functions normally for quite a while. In addition, emotions and feelings are intimately associated with bowel function. The mechanisms of communication are complex and include immune, neural, endocrine, and metabolic pathways [17]. Preclinical studies have revealed the important role played by the vagus nerve $(\mathrm{VN})$ in the neural link between gut microbes and centrally mediated behavioral effects. The gut microbiota regulates key central neurotransmitters by altering levels of precursors; it has been demonstrated that some gut bacteria raise plasma tryptophan levels and thus influence central 5-HT transmission and release of neurotransmitters such as $\gamma$-aminobutyric acid, noradrenaline, serotonin, or acetylcholine $[16,18]$. These microbially synthesized neurotransmitters can cross the mucosal layer of the intestines and may mediate physiological events in the brain. Latterly, the gut microbiota has been involved in different neurological diseases including depression, autism, schizophrenia, and Parkinson's disease. Whether or not changes in the intestinal microbiota are essential to the pathophysiology of such diseases or are simply epiphenomenal, is still debatable and under intense research focus.

\section{Microbiota-Gut-Brain Axis}

\subsection{Concepts and Brief Mechanism of Microbiota-Gut-Brain Axis}

The microbiota, the intestine and the brain communicate through the microbiota-gutbrain axis and a disturbance of this axis is involved in the pathophysiology of neurodegenerative disorders [19]. A disturbance of this axis is also involved in the pathophysiology of several diseases, such as obesity and diabetes [19].

The gut microbiota talks to the brain by producing bioactive short-chain fatty acids (SCFAs) that can be absorbed and therefore enter the circulation and they are fairly shortlived detected at relatively low concentrations [20]. There is not a lot of evidence to suggest that at physiologically relevant levels that they enter the brain [21]. They have another mechanism when they can bind G-protein-coupled receptors such as free fatty acid receptors 2 and 3 (FFAR2/3) and importantly cells of the immune system express these receptors [22]. The immune system is talking to the brain and there are involved both humoral and neural pathways and there is the same possibility in the gut-brain axis where the humoral pathway it is probably not the SCFA directly accessing the brain but rather inducing hormonal changes in the periphery regulating immune function [23]. The visceral sensory pathway is important to the nucleus tract solitaire. In this area, neurons project to the limbic system including areas such as the amygdala which is involved in the regulation of emotional behavior all of which are affected by the gut microbiota. The pathways of communication are starting to be illuminated which creates even better opportunities for manipulating this pathway to improve health [24].

It is well known that the gut talks to the brain, but this dialogue is bi-directional. Therefore, it is not just the microbes or the immune system in the gut talking to the brain but it is also the brain talking back to the immune system or to the gut. Therefore, there is this two-way communication that goes back and forth regulatory feedback that leads to health or to dysbiosis of the gut, damage of the brain, and the whole body [25]. For example, gut metabolites can cross the intestine barrier or be recognized by receptors on the barrier to induce satiety. In the opposite direction, hormones produced by the host can affect the gut microbiota and gut health. Noradrenaline released by the adrenergic nerve can interact with certain Gram-negative bacteria in the gut and cause them to grow or be more virulent. Indeed, chronic stress which increases norepinephrine can cause dysbiosis and gut disease [26]. Therefore, diet has a big effect on our gut microbiota and its function.

It is bi-directional communication between our brain and the gastro-intestinal (GI) system and it has been used to explain the intestinal function and even the perturbation whether acute or chronic. The components of the gut-brain axis is represented in Figure 1: the first is the gut-brain communication and that is known that there are two components to this the intrinsic and the extrinsic pathways [27]. There is an enteral nervous system, 
the myenteric plexus and the submucosal plexus which have a very intricate array of communication and use various receptors: the mechanoreceptors, the thermal receptor, the chemoreceptors and osmoreceptors. The sensory neurons sense, the particular stimulus and then pass it through the interneurons, to the motor neurons which can help in different functions such as the secretion, maintenance of the motility and absorptive functions of the gastrointestinal tract. It is important to understand that the enteral nervous system can function even in the absence of the CNS [28]. The VN is still the part of the colon and then it is a pelvic nerve that communicates through the nodose ganglion and then communicates to the CNS [29]. The second one is the spinal pathway through various nerves from T5 to L5 which eventually land up through the paravertebral ganglia into the spinal cord and then communicate to the CNS. VN apart from bi-directional communication it also can generate immune responses to microbial metabolites and has a well-recognized cholinergic anti-inflammatory pathway [30]. Therefore, it can pick up changes in the microbiota and also transmit inflammatory responses. From all the signal that reaches the hypothalamus of the brain stem, only a part of them is allowed to the cerebral cortex and these are processed there. Stress, which could be interoceptive (inflammation and infection) or exteroceptive (life events), results in a neuroendocrine response which can through the autonomic nervous system or sensory modulation may affect the GI system [31]. Therefore, this completes the bidirectional loop through the hormonal neural and immunological mechanisms. A more important and increasingly recognized thing is the gut microbiota, which is a very important component of this entire axis. It is recognized that the CNS can alter the gut microbiota changes in GI motility and through various neurotransmitters. Microbiota also affects the brain and can through the enterochromaffin mediate responses to the CNS via VN [32]. The gut microbiota is continuously sampled through the $\mathrm{M}$ cells and the antigens are presented to the dendritic cells, but there is a controlled inflammation part of it is also because of the dietary fiber which promotes a certain type of microbiota formation of SCFA and these results in regulatory response, but in conditions of dysbiosis immune response through secretion of various cytokines and this can impact the VN endings or the enteral nervous system.

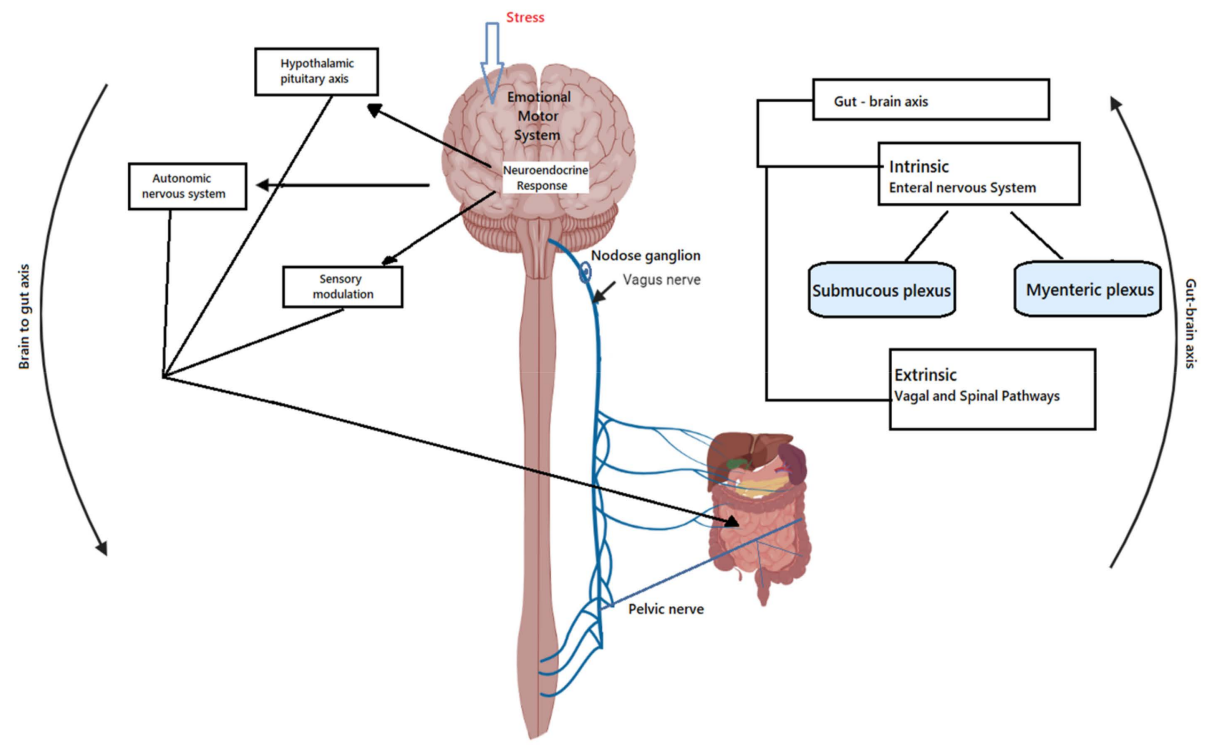

Figure 1. Bi-directional communications between gut and brain.

\subsection{Recent Trends on Studies between VN and Microbiota in Different Disease}

$\mathrm{VN}$ is the longest and the most important nerve in the body. It innervates all the organs in the body: heart, lungs, liver, pancreas, spleen, stomach, kidneys and obvious it has projections into the brain. VN is involved in almost every chronic disease. If the VN does not function correctly the brain, the brainstem and all the organs could be affected. 
If are followed the neurology of every disease, the cause is VN. The VN can also sense the microbiota and can transfer this sensed information to the central nervous system. Then, central system can generate a response; the latter could perpetuate a pathological condition of the digestive tract or promote neurodegenerative disorders [22]. A dysbiosis is observed in obesity and diabetes. Therefore, $\mathrm{VN}$ can be seen as the interface of the braingut communication axis [23,33]. When the vagal tone is low, it is very easy to contract disease and it is described in obesity and diabetes too [24]. Stimulation can help improve the $\mathrm{VN}$ damage and stimulate the body to repair and also could restore homeostasis in such diseases. Furthermore, VN stimulation used for the treatment of depression and epilepsy [25] and its anti-inflammatory properties such as in obesity and diabetes [26], should be of interest.

If the $\mathrm{VN}$ malfunctions, significant effects can be seen on appetite and eating acting as a regulator of body weight [34]. Microbes control eating behavior by influencing signals that are delivered to the brain and by the $\mathrm{VN}$ and two of the most important hormones dopamine and serotonin [35]. Dopamine is associated with motivation, reward [34] and serotonin plays a role in cognition, mood, memory, and executive functions [36]. Approximately $50 \%$ of the dopamine in the body is produced in the gut and also L-dopamine that is used to treat Parkinson's disease [37], while all the serotonin in the body is made also in the gut [36]. Serotonin deficiency is linked to depression and neurological disfunction [38]. Therefore microbes by control just these two hormones can influence our mood, behavior, anxiety, relaxation, sleep, and eating.

Neurotransmitters produced in the gut which regulate appetite, peptide YY, pancreatic polypeptide, glucagon-like peptide- 1 and oxyntomodulin suppress appetite, whilst ghrelin increases appetite [39]. There is an equilibrium of these two types that determine the appetite, adjusting eating behavior. The gut microbes can alter the level of these hormones since they are mainly produced in the gut. The probiotic bacteria can raise the level of this amino acid tryptophan which is important because it is involved in producing these hormones (for example leptin, ghrelin, PYY that influence appetite) [6]. In conclusion, microbiota can influence both directly and indirectly the eating behavior and appetite control [40]. Microbiota products that can alter the host behavior and health are: fatty acids that influence energy, metabolism and immunity; biotin that influence cell growth and metabolism; vitamin $\mathrm{K}$ that produce blood coagulation; tryptophan, serotonin, dopamine, GABA, noradrenaline, acetylcholine which are neurotransmitters and influence brain functions [41].

\section{Diabetes}

High blood sugar can lead to diabetes, which affects over one in 10 humans [42]. Type 1 diabetes (T1D) is thought to be an autoimmune condition where the immune system mistakenly attacks the body, and it is defined by destroyed pancreatic cells which result in impaired insulin secretion and hyperglycemia [43]. Dysbiosis of microbiota on T1D was reported in various studies during the last few years, concluding that the microbial diversity is reduced in T1D patients [44-46]. Decreasing levels of Bacteroides compared to an increasing level of Firmicutes was observed [47], [48]. Metagenomic studies showed a decrease in Clostridium Clusters IV and XIV and Prevotella and Akkermansia bacteria in T1D patients $[49,50]$. However, one complication of T1D receives less attention than the others: cognitive dysfunction [51]. Previous studies reported that modification of gut microbiota can reduce the incidence of T1D [52-54]. Therefore, researchers from Wenzhou Medical University hypothesized that modified gut microbiota may also affect cognitive function in T1D [55]. Using an induced mouse model of T1D, researchers modified the microbiota with an antibiotic and measured the impact of these microbial changes on cognitive performance. Antibiotic-treated mice had a disrupted microbiome and altered host metabolic phenotypes. Antibiotic-treated mice also showed greater cognitive impairment than induced T1D alone. The antibiotic treatment depleted acetate-producing bacteria, which lead to long-term acetate deficiency. This deficiency then resulted in a reduction of synaptophysin in the 
hippocampus. Acetate supplementation or fecal microbiota transplantation led to the recovery of hippocampal synaptophysin levels. This effect was dependent on the VN function. These results suggest a novel protective role of microbiome-generated acetate in cognitive function and suggest that long-term acetate deficiency is a risk factor for cognitive decline.

Only $10 \%$ of diabetic people have T1D, whereas the remainder has Type 2 Diabetes (T2D) [42]. T2D can be caused by lifestyle factors such as an unhealthy diet and lack of exercise, it is more common and typically occurs in adults [56,57]. T2D is a metabolic disease it is related to dysbiosis of microbiota [58-60]. In addition, diabetes can cause a problem for the entire body including the brain [61,62]. High blood sugar damages small arteries carrying oxygen-rich blood to the brain, so blood-brain cells can die. This may lead to a decline in memory and other cognitive functions, leading eventually to a type of dementia known as vascular dementia [63]. Having diabetes can increase the risk of Alzheimer's disease as well [64]. People who do not have diabetes but whose blood glucose levels are above normal, a category is known as pre-diabetes, are also more likely to develop cognitive problems [65]. Both types of diabetes patients are at risk of major depressive disorder $[66,67]$.

How do these things affect diabetes? It is known that these efferent signals which were results of the inflammatory process [68] are transmitted to the brain and from there, various signals go on to the various organs and these may change the glucose metabolism [69]. Therefore, glucose metabolism is affected by the changes in the gut microbiota [70]. The most evidence comes from the mice study [71-73]. Therefore, in germ-free mice, they are relatively resistant to diet-induced obesity [72]. However, if the microbiota of conventionally raised mice is transferred to these germ-free mice, they have an increased body fat content and insulin resistance [74]. It is also recognized that a high-fat diet is associated with the development of insulin resistance and knockout of the TLR5 receptor in mice could result in diabetic phenotype [75]. This is mediated to alterations in the gut microbiota increase in the intestinal inflammation and also GIP and GLP1, that in the alteration in the incretin response [76].

From human studies, it is recognized that there is an alteration in the ratio of Firmicutes/Bacteroides with the level of Proteobacteria increased in the patients with T2D [77-79]. Diabetics also have a lower abundance of Akkermansia muciniphila [80] and this increases with butyrate supplementation and even with drugs such as metformin [80]. In animal studies, this has been shown to improve glucose tolerance [81]. A well-documented review by Gurung et al. [59] associated the presence of Ruminococcus (Firmicutes phylum) and Fusobacterium bacteria with T2D. Therefore, does modulation of microbiota helps? There are a lot of studies that suggest probiotics such as Lactobacillus and Bifidobacterium could improve insulin resistance [82], however, the effect size, unfortunately, is low and so is the case with dietary fibers also [83].

\section{EEG Normal Rhythms and Modification in Diabetes}

The latest studies shown that VN stimulation induces EEG changes [84]. Therefore, it is plausible that changes in the microbiota composition profile due to obesity and diabetes are modulated by the VN and can be captured through EEG signaling.

An integrative understanding of the mechanism that subserves the relationship between the gut, the brain and also the metabolic diseases, in this case, diabetes, will need to take into consideration. One mechanism that is very intensively used to investigate the abnormalities of brain functioning is electroencephalography (EEG) [85]. EEG is based on low costs and in addition, it is fully noninvasive.

To work with EEG signals and to extract useful information and features that help in the early diagnosis of neurological diseases related to diabetes, the rhythmic activity of the EEG should be understood. A clinical EEG wave has an amplitude between 10 and $100 \mu \mathrm{V}$ and a frequency range of $1 \mathrm{~Hz}$ to $100 \mathrm{~Hz}$ [86]. EEG has five rhythms with different frequency bands. The most clinically relevant bands are: alpha $(8-12 \mathrm{~Hz})$, beta $(13-30 \mathrm{~Hz})$, 
theta $(3.5-7.5 \mathrm{~Hz})$ delta $(<3 \mathrm{~Hz})$ and gamma $(31-44 \mathrm{~Hz})$ [87]. Alpha rhythm consists of continuous oscillations, modeled in amplitude and it appears in the waking period, in physical and mental relaxation and is present in people beginning at 2 years old. It is best detected when the subject has their eyes closed. The alpha rhythm attenuates with the opening of the eyes and is best observed in the visual cortex (occipital) [88]. Alpha activity normally disappears in attention states (stress, open eyes, mental operations). Beta occurs in normal adult subjects, especially in the precentral regions. Low amplitude (1-10 $\mu \mathrm{V}$, rarely up to $20 \mu \mathrm{V}$ ) with multiple and varied frequencies is often associated with intense activities and active concentration. Beta rhythm is also associated with various pathologies or effects of barbiturate drugs [89]. Delta occurs in young children or some neurological diseases. They normally occur in deep sleep at adults as well as at children. This waveform can be recorded frontally in adults and posteriorly in children [90]. Theta is associated with the waking-sleep transition state in children, adolescents, and young adults. It can be produced by hyperventilation. This rhythm can also occur during trance or hypnosis state. They normally appear in sleep at any age. In awake adults, they are considered abnormal if they occur in excess. Theta wave is recorded across the temporal and parietal region of the scalp [89]. Gamma rhythm seems to be involved in higher mental activities including perception, fear, solving problems, etc. Until late adulthood, the activities of delta and theta rhythms are reduced with age, whereas those of alpha and beta waves increase linearly [91]. An inverse relationship has been observed between delta and glucose metabolism in the case of neurological diseases within the prefrontal cortex as a consequence of dementia cognitive impairment (DCI) [92].

Studies on patients with T2D vs healthy subjects, described in Table 1, use basic signal processing methods such as spectral analysis or Fourier transform combined with statistical analysis revealed significantly decreased in delta and theta bands of the T2D group [93] or decrease in resting EEG beta activity over the central and posterior region [94]. Frøkjær et al. [95] observed a decreased EEG power in the delta $(1-4 \mathrm{~Hz})$ and gamma $(30-45 \mathrm{~Hz})$ bands in diabetic patients. Topographic analysis revealed that these changes were confirmed to the frontal region for the delta band and to central cortical areas for the gamma band. C. Benwell et al. [96] used absolute power estimates to compute the spectral power ratio and statistical analysis (ANOVA, MANOVA) and observed that T2D is specifically associated with a reduction of alpha power in the temporal regions, with no significant differences observed in other brain regions. In addition, a review of A. Baskaran et al. [97] reported the changes in EEG rhythms in T2D and also T1D. Studies on T2D patients demonstrated decreased alpha band power in the posteriors temporal brain region and also beta band power in the temporal brain area. Theta and delta power was reported to have increased activity over the frontal and parieto-occipital brain region. In the posterior and central brain areas have been observed also the increase of P300 latency and decrease of N100 amplitude. In T1D patients was observed a decreasing band power of alpha, beta and gamma rhythms in the temporal and posterior temporal brain region and an increasing of theta and delta band power in the frontal and parieto-occipital brain area.

Table 1. Relevant studies on EEG modification for T2D patients.

\begin{tabular}{ccc}
\hline Data and Methods & EEG Modification & Paper \\
\hline $\begin{array}{c}\text { Signal acquisition for 27 healthy subjects used as control } \\
\text { and 24 patients with longstanding diabetes mellitus } \\
\text { (DM) and signs of autonomic dysfunction. The power } \\
\text { distribution based on wavelet analysis }\end{array}$ & $\begin{array}{c}\text { Decreased EEG power in the delta (1-4 Hz) and gamma } \\
(30-45 \mathrm{~Hz}) \text { bands on DM patients. }\end{array}$ \\
$\begin{array}{c}\text { [95] } \\
\text { EEG recorded for 28 patients with T2D: 16 amnesic mild } \\
\begin{array}{c}\text { Phase lag index (PLI) used for frequency band } \\
\text { decomposition and grouped into long distance }\end{array}\end{array}$ & $\begin{array}{c}\text { Significant decrease of global mean PLI in lower alpha, } \\
\text { upper alpha and beta bands observed on aMCI subjects. }\end{array}$ \\
\hline
\end{tabular}


Table 1. Cont.

\begin{tabular}{|c|c|c|}
\hline Data and Methods & EEG Modification & Paper \\
\hline $\begin{array}{l}\text { EEG signal acquisition for } 19 \text { patients with T2D: } 8 \text { aMCI } \\
\text { patients and } 11 \text { controls. Multivariate synchronization } \\
\text { algorithms (S-estimator (S), synchronization index (SI), } \\
\text { and global synchronization index (GSI)) }\end{array}$ & $\begin{array}{l}\text { The synchronization values estimated by S, SI, and GSI } \\
\text { methods decreased significantly in delta and theta bands of } \\
\text { the aMCI group than the T2D group. }\end{array}$ & [93] \\
\hline $\begin{array}{l}72 \text { adults: T2D-27 participants with no subjective } \\
\text { cognitive complaints, } 27 \text { healthy control patients, and } 18 \\
\text { Alzheimer's disease patients. Absolute power estimates } \\
\text { used to compute the spectral power ratio and statistical } \\
\text { analysis (ANOVA, MANOVA) }\end{array}$ & $\begin{array}{l}\text { Decreasing of } \alpha \text { power in the temporal regions of } \\
\text { T2M patients }\end{array}$ & [96] \\
\hline $\begin{array}{c}\text { T2D-28 participants, } 21 \text { healthy control patients. } \\
\text { Spectral analysis was performed using a Hamming } \\
\text { window and a fast Fourier transform, statistical analysis } \\
\text { (MANOVA) }\end{array}$ & $\begin{array}{c}\text { Decrease in N100 amplitude, increase in P300, and decrease } \\
\text { in resting EEG beta activity over central and posterior } \\
\text { regions for T2D subjects }\end{array}$ & [94] \\
\hline $\begin{array}{c}\text { EEG recorded for } 28 \text { patients with T2D ( } 16 \text { aMCI } \\
\text { patients and } 12 \text { controls). The relative power and the } \\
\text { coherence together with Statistical analysis (Wilcoxon } \\
\text { rank-sum test) was used. }\end{array}$ & 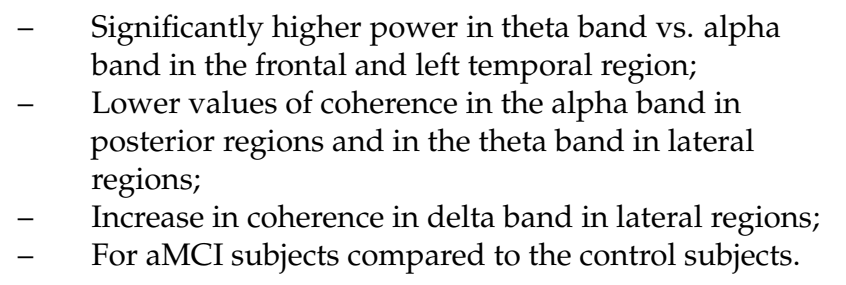 & [99] \\
\hline $\begin{array}{l}\text { EEG signal acquisition for } 27 \text { T2D subjects-17 aMCI } \\
\text { and } 10 \text { healthy control subjects. Correlation between } \\
\text { probabilities of recurrence (CPR) and statistical analysis }\end{array}$ & $\begin{array}{c}\text { The CPR values were lower for aMCI than of the } \\
\text { control group. }\end{array}$ & [100] \\
\hline $\begin{array}{l}\text { EEG recorded for } 20 \text { elderly patients with T2D and } 20 \\
\text { normal subjects in the same age group. Statistical } \\
\text { analysis: Independent sample " } \mathrm{t} \text { " test }\end{array}$ & $\begin{array}{l}\text { Slow EEG activity in the central cortex and reduced alpha } \\
\text { activity in the parietal area for T2D. Decreased relative alpha } \\
\text { power, from the effects of hyperglycemia for nondiabetics. }\end{array}$ & [101] \\
\hline $\begin{array}{l}\text { EEG recording for } 35 \text { male patients with T2D on oral } \\
\text { hypoglycemic medication and } 35 \text { healthy subjects } \\
\text { (controls) during and after hyperventilation (HV). } \\
\text { Quantitative EEG analysis using Fast Fourier } \\
\text { Transformation. EEG power spectra compared using } \\
\text { Student's } t \text {-test }\end{array}$ & $\begin{array}{l}\text { - A diffuse increase in low-frequency slow waves at } \\
\text { delta range and high-frequency fast waves at beta } \\
\text { range for T2D patients compared to the controls in } \\
\text { EEG during HV. } \\
\text { A prolonged existence of delta activity at a few brain } \\
\text { regions and beta activity in some brain regions in the } \\
\text { EEG after cessation of HV during post-HV. }\end{array}$ & [102] \\
\hline
\end{tabular}

\section{Conclusions}

The topic of the gut-brain axis has been much debated in recent years, but we believe that although it is quite obvious, this mechanism of communication between these two organs is not yet fully understood. The microbiota has a central role in this connection and its dysbiosis creates disorders in both directions. EEG is a non-invasive, inexpensive, and readily available technique for analyzing the brain's electrical activity which could help find a specific pattern for people with diabetes/metabolic disease. Given that neurological diseases respond a lot better when treatment is started in the early stages of the disease, investigating EEG in patients with diabetes and understanding the specific effects of the brain in diabetes could prevent the severity of neurological diseases related to it. This is a challenge and at the same time a promise for the prevention of neurological diseases associated with microbiota dysbiosis. Furthermore, $40 \%$ of patients with diabetes are at risk for developing a neurological disease: from dementia to even Alzheimer's disease, but if they identified a specific pattern and EEG would become a routine investigation for these patients, we could improve the quality of life of many individuals or their families by exempting of complications of such a disease. Drug treatments applied in the early stages of a neurological disease can make a difference. In addition, the connection with intestinal microbiota could count in the sense that changing lifestyle, diet, probiotic consumption 
or even transplanting the microbiota could lead to improved gut health and at the same time the brain. Investigating the EEG brain signals of patients with metabolic syndrome can be discovered in some patterns which will lead to developing new ways of restoring the intestinal flora to prevent and manage metabolic diseases such as obesity and diabetes as well neurological diseases. Thus, so far, standard methods of signal processing have been used to detect changes in the EEG, but certainly, advanced processing methods would better distinguish specific patterns. Future work can investigate other diseases related with microbiota dysbiosis such as Crohn's diseases [103], rheumatoid arthritis [104], atherosclerosis [105], and inflammatory bowel diseases [106]. Patients with this pathology can be also candidates selected for the study of the EEG signals related with microbiota. This area of research represents a real goldmine that no doubt will open major avenues of future research constituting the basis for shaping prevention and therapeutic strategies with major health implications.

Author Contributions: R.T., M.D. and C.C. participated in drafting, editing, and writing the manuscript. R.T. and M.D. designed the figure. R.T., M.D. and C.C. approved the final version of the manuscript. All authors have read and agreed to the published version of the manuscript.

Funding: This paper was supported by the project "DECIDE-Development through entrepreneurial education and innovative doctoral and postdoctoral research, project code POCU/380/6/13/125031, project co-financed from the European Social Fund through the 2014-2020 Operational Program Human Capital.

Institutional Review Board Statement: Not applicable.

Informed Consent Statement: Not applicable.

Conflicts of Interest: The authors declare no conflict of interest.

\section{References}

1. Al-Asmakh, M.; Zadjali, F. Use of Germ-Free Animal Models in Microbiota-Related Research. J. Microbiol. Biotechnol. 2015, 25, 1583-1588. [CrossRef] [PubMed]

2. Uzbay, T. Germ-free animal experiments in the gut microbiota studies. Curr. Opin. Pharmacol. 2019, 49, 6-10. [CrossRef] [PubMed]

3. Mayer, E.A.; Tillisch, K.; Gupta, A. Gut/brain axis and the microbiota. J. Clin. Investig. 2015, 125, 926-938. [CrossRef] [PubMed]

4. Maynard, C.L.; Elson, C.O.; Hatton, R.; Weaver, C.T. Reciprocal interactions of the intestinal microbiota and immune system. Nature 2012, 489, 231-241. [CrossRef]

5. Flint, H.J.; Scott, K.P.; Louis, P.; Duncan, S. The role of the gut microbiota in nutrition and health. Nat. Rev. Gastroenterol. Hepatol. 2012, 9, 577-589. [CrossRef]

6. Covasa, M.; Stephens, R.W.; Toderean, R.; Cobuz, C. Intestinal Sensing by Gut Microbiota: Targeting Gut Peptides. Front. Endocrinol. 2019, 10, 82. [CrossRef]

7. Shabana; Shahid, S.U.; Irfan, U. The gut microbiota and its potential role in obesity. Futur. Microbiol. 2018, 13, 589-603. [CrossRef]

8. Haluzík, M.; Kratochvílová, H.; Haluzíková, D.; Mraz, M. Gut as an emerging organ for the treatment of diabetes: Focus on mechanism of action of bariatric and endoscopic interventions. J. Endocrinol. 2018, 237, R1-R17. [CrossRef]

9. Knip, M.; Honkanen, J. Modulation of Type 1 Diabetes Risk by the Intestinal Microbiome. Curr. Diabetes Rep. 2017, 17, 105. [CrossRef]

10. Eom, T.; Kim, Y.S.; Choi, C.H.; Sadowsky, M.; Unno, T. Current understanding of microbiota- and dietary-therapies for treating inflammatory bowel disease. J. Microbiol. 2018, 56, 189-198. [CrossRef]

11. Cahill, F.; Ji, Y.; Wadden, D.; Amini, P.; Randell, E.; Vasdev, S.; Gulliver, W.; Sun, G. The Association of Serum Total Peptide YY (PYY) with Obesity and Body Fat Measures in the CODING Study. PLoS ONE 2014, 9, e95235. [CrossRef]

12. Pekmez, C.T.; Dragsted, L.O.; Brahe, L.K. Gut microbiota alterations and dietary modulation in childhood malnutrition-The role of short chain fatty acids. Clin. Nutr. 2019, 38, 615-630. [CrossRef]

13. Amitay, E.L.; Krilaviciute, A.; Brenner, H. Systematic review: Gut microbiota in fecal samples and detection of colorectal neoplasms. Gut Microbes 2018, 9, 293-307. [CrossRef]

14. Lv, F.; Chen, S.; Wang, L.; Jiang, R.; Tian, H.; Li, J.; Yao, Y.; Zhuo, C. The role of microbiota in the pathogenesis of schizophrenia and major depressive disorder and the possibility of targeting microbiota as a treatment option. Oncotarget 2017, 8, 100899-100907. [CrossRef]

15. Winter, G.; Hart, R.A.; Charlesworth, R.; Sharpley, C. Gut microbiome and depression: What we know and what we need to know. Rev. Neurosci. 2018, 29, 629-643. [CrossRef] [PubMed]

16. Dinan, T.; Cryan, J.F. Gut instincts: Microbiota as a key regulator of brain development, ageing and neurodegeneration: Microbiota-gut-brain axis across the lifespan. J. Physiol. 2016, 595, 489-503. [CrossRef] [PubMed] 
17. Sommer, F.; Bäckhed, F. Know your neighbor: Microbiota and host epithelial cells interact locally to control intestinal function and physiology. BioEssays 2016, 38, 455-464. [CrossRef] [PubMed]

18. Mahony, S.O.; Clarke, G.; Borre, Y.; Dinan, T.; Cryan, J. Serotonin, tryptophan metabolism and the brain-gut-microbiome axis. Behav. Brain Res. 2015, 277, 32-48. [CrossRef]

19. Zagon, A. Does the vagus nerve mediate the sixth sense? Trends Neurosci. 2001, 24, 671-673. [CrossRef]

20. Hernández, M.A.G.; Canfora, E.E.; Jocken, J.W.; Blaak, E.E. The Short-Chain Fatty Acid Acetate in Body Weight Control and Insulin Sensitivity. Nutrients 2019, 11, 1943. [CrossRef]

21. Silva, Y.P.; Bernardi, A.; Frozza, R.L. The Role of Short-Chain Fatty Acids From Gut Microbiota in Gut-Brain Communication. Front. Endocrinol. 2020, 11, 25. [CrossRef]

22. Mishra, S.P.; Karunakar, P.; Taraphder, S.; Yadav, H. Free Fatty Acid Receptors 2 and 3 as Microbial Metabolite Sensors to Shape Host Health: Pharmacophysiological View. Biomedicines 2020, 8, 154. [CrossRef]

23. Wu, Y.; Xu, H.; Tu, X.; Gao, Z. The Role of Short-Chain Fatty Acids of Gut Microbiota Origin in Hypertension. Front. Microbiol. 2021, 12, 730809. [CrossRef] [PubMed]

24. Kim, J.; Kirkland, R.; Lee, S.; Cawthon, C.; Rzepka, K.; Minaya, D.; de Lartigue, G.; Czaja, K.; de La Serre, C. Gut microbiota composition modulates inflammation and structure of the vagal afferent pathway. Physiol. Behav. 2020, 225, 113082. [CrossRef] [PubMed]

25. Martin, C.R.; Osadchiy, V.; Kalani, A.; Mayer, E.A. The Brain-Gut-Microbiome Axis. Cell. Mol. Gastroenterol. Hepatol. 2018, 6, 133-148. [CrossRef]

26. Cryan, J.F.; O’Riordan, K.J.; Cowan, C.S.M.; Sandhu, K.V.; Bastiaanssen, T.F.S.; Boehme, M.; Codagnone, M.G.; Cussotto, S.; Fulling, C.; Golubeva, A.V.; et al. The Microbiota-Gut-Brain Axis. Physiol. Rev. 2019, 99, 1877-2013. [CrossRef]

27. Carabotti, M.; Scirocco, A.; Maselli, M.A.; Severi, C. The gut-brain axis: Interactions between enteric microbiota, central and enteric nervous systems. Ann. Gastroenterol. 2015, 28, 203-209.

28. Lai, N.Y.; Mills, K.; Chiu, I.M. Sensory neuron regulation of gastrointestinal inflammation and bacterial host defence. J. Intern. Med. 2017, 282, 5-23. [CrossRef]

29. Browning, K.N.; Travagli, R.A. Central Nervous System Control of Gastrointestinal Motility and Secretion and Modulation of Gastrointestinal Functions. Compr. Physiol. 2014, 4, 1339-1368. [CrossRef]

30. Bonaz, B.; Sinniger, V.; Pellissier, S. Therapeutic Potential of Vagus Nerve Stimulation for Inflammatory Bowel Diseases. Front. Neurosci. 2021, 15, 650971. [CrossRef] [PubMed]

31. Stengel, A.; Taché, Y. Neuroendocrine Control of the Gut During Stress: Corticotropin-Releasing Factor Signaling Pathways in the Spotlight. Annu. Rev. Physiol. 2009, 71, 219-239. [CrossRef]

32. Bellono, N.W.; Bayrer, J.R.; Leitch, D.B.; Castro, J.; Zhang, C.; O’Donnell, T.A.; Brierley, S.; Ingraham, H.A.; Julius, D. Enterochromaffin Cells Are Gut Chemosensors that Couple to Sensory Neural Pathways. Cell 2017, 170, 185.e16-198.e16. [CrossRef]

33. Pellissier, S.; Dantzer, C.; Mondillon, L.; Trocme, C.; Gauchez, A.-S.; Ducros, V.; Mathieu, N.; Toussaint, B.; Fournier, A.; Canini, F.; et al. Relationship between Vagal Tone, Cortisol, TNF-Alpha, Epinephrine and Negative Affects in Crohn's Disease and Irritable Bowel Syndrome. PLoS ONE 2014, 9, e105328. [CrossRef]

34. De Lartigue, G. Role of the vagus nerve in the development and treatment of diet-induced obesity: The role of the vagus nerve in obesity. J. Physiol. 2016, 594, 5791-5815. [CrossRef]

35. Briguglio, M.; Dell'Osso, B.; Panzica, G.; Malgaroli, A.; Banfi, G.; Dina, C.Z.; Galentino, R.; Porta, M. Dietary Neurotransmitters: A Narrative Review on Current Knowledge. Nutrients 2018, 10, 591. [CrossRef]

36. Jenkins, T.A.; Nguyen, J.C.D.; Polglaze, K.E.; Bertrand, P.P. Influence of Tryptophan and Serotonin on Mood and Cognition with a Possible Role of the Gut-Brain Axis. Nutrients 2016, 8, 56. [CrossRef]

37. Liu, J.; Xu, F.; Nie, Z.; Shao, L. Gut Microbiota Approach-A New Strategy to Treat Parkinson's Disease. Front. Cell. Infect. Microbiol. 2020, 10, 570658. [CrossRef]

38. Cowen, P.J.; Browning, M. What has serotonin to do with depression? World Psychiatry 2015, 14, 158-160. [CrossRef] [PubMed]

39. Suzuki, K.; Simpson, K.A.; Minnion, J.; Shillito, J.C.; Bloom, S.R. The role of gut hormones and the hypothalamus in appetite regulation. Endocr. J. 2010, 57, 359-372. [CrossRef] [PubMed]

40. Alcock, J.; Maley, C.C.; Aktipis, C.A. Is eating behavior manipulated by the gastrointestinal microbiota? Evolutionary pressures and potential mechanisms. BioEssays 2014, 36, 940-949. [CrossRef]

41. Rowland, I.; Gibson, G.; Heinken, A.; Scott, K.; Swann, J.; Thiele, I.; Tuohy, K. Gut microbiota functions: Metabolism of nutrients and other food components. Eur. J. Nutr. 2018, 57, 1-24. [CrossRef] [PubMed]

42. World Health Organization. Global Report on Diabetes; World Health Organization: Geneva, Switzerland, 2016. Available online: https:/ / apps.who.int/iris/handle/10665/204871 (accessed on 13 October 2021).

43. DiMeglio, L.A.; Evans-Molina, C.; Oram, R. Type 1 diabetes. Lancet 2018, 391, 2449-2462. [CrossRef]

44. Zaky, A.; Glastras, S.J.; Wong, M.Y.W.; Pollock, C.A.; Saad, S. The Role of the Gut Microbiome in Diabetes and Obesity-Related Kidney Disease. Int. J. Mol. Sci. 2021, 22, 9641. [CrossRef]

45. Traversi, D.; Rabbone, I.; Ignaccolo, M.G.; Carletto, G.; Racca, I.; Vallini, C.; Andriolo, V.; Cadario, F.; Savastio, S.; Siliquini, R.; et al. Gut microbiota diversity and T1DM onset: Preliminary data of a case-control study. Hum. Microbiome J. 2017, 5-6, 11-13. [CrossRef] 
46. Leiva-Gea, I.; Sánchez-Alcoholado, L.; Martín-Tejedor, B.; Castellano-Castillo, D.; Moreno-Indias, I.; Urda-Cardona, A.; Tinahones, F.J.; Fernández-García, J.C.; Queipo-Ortuño, M.I. Gut Microbiota Differs in Composition and Functionality Between Children With Type 1 Diabetes and MODY2 and Healthy Control Subjects: A Case-Control Study. Diabetes Care 2018, 41, $2385-2395$. [CrossRef]

47. Mejía-León, M.E.; Petrosino, J.F.; Ajami, N.J.; Domínguez-Bello, M.G.; De La Barca, A.M.C. Fecal microbiota imbalance in Mexican children with type 1 diabetes. Sci. Rep. 2015, 4, 3814. [CrossRef]

48. Pellegrini, S.; Sordi, V.; Bolla, A.M.; Saita, D.; Ferrarese, R.; Canducci, F.; Clementi, M.; Invernizzi, F.; Mariani, A.; Bonfanti, R.; et al. Duodenal Mucosa of Patients With Type 1 Diabetes Shows Distinctive Inflammatory Profile and Microbiota. J. Clin. Endocrinol. Metab. 2017, 102, 1468-1477. [CrossRef]

49. De Groot, P.; Nikolic, T.; Pellegrini, S.; Sordi, V.; Imangaliyev, S.; Rampanelli, E.; Hanssen, N.; Attaye, I.; Bakker, G.; Duinkerken, G.; et al. Faecal microbiota transplantation halts progression of human new-onset type 1 diabetes in a randomised controlled trial. Gut 2021, 70, 92-105. [CrossRef] [PubMed]

50. Zhou, H.; Zhao, X.; Sun, L.; Liu, Y.; Lv, Y.; Gang, X.; Wang, G. Gut Microbiota Profile in Patients with Type 1 Diabetes Based on $16 S$ rRNA Gene Sequencing: A Systematic Review. Dis. Markers 2020, 2020, 3936247. [CrossRef] [PubMed]

51. Ryan, C.M.; Van Duinkerken, E.; Rosano, C. Neurocognitive consequences of diabetes. Am. Psychol. 2016, 71, 563-576. [CrossRef]

52. Han, H.; Li, Y.; Fang, J.; Liu, G.; Yin, J.; Li, T.; Yin, Y. Gut Microbiota and Type 1 Diabetes. Int. J. Mol. Sci. 2018, 19, 995. [CrossRef]

53. Dedrick, S.; Sundaresh, B.; Huang, Q.; Brady, C.; Yoo, T.; Cronin, C.; Rudnicki, C.; Flood, M.; Momeni, B.; Ludvigsson, J.; et al. The Role of Gut Microbiota and Environmental Factors in Type 1 Diabetes Pathogenesis. Front. Endocrinol. 2020, 11, 78. [CrossRef]

54. Siljander, H.; Honkanen, J.; Knip, M. Microbiome and type 1 diabetes. EBioMedicine 2019, 46, 512-521. [CrossRef]

55. Zheng, H.; Xu, P.; Jiang, Q.; Xu, Q.; Zheng, Y.; Yan, J.; Ji, H.; Ning, J.; Zhang, X.; Li, C.; et al. Depletion of acetate-producing bacteria from the gut microbiota facilitates cognitive impairment through the gut-brain neural mechanism in diabetic mice. Microbiome 2021, 9, 145. [CrossRef]

56. Wu, Y.; Ding, Y.; Tanaka, Y.; Zhang, W. Risk Factors Contributing to Type 2 Diabetes and Recent Advances in the Treatment and Prevention. Int. J. Med. Sci. 2014, 11, 1185-1200. [CrossRef] [PubMed]

57. Asif, M. The prevention and control the type-2 diabetes by changing lifestyle and dietary pattern. J. Educ. Health Promot. 2014, 3, 1. [CrossRef]

58. Huda, M.N.; Kim, M.; Bennett, B.J. Modulating the Microbiota as a Therapeutic Intervention for Type 2 Diabetes. Front. Endocrinol. 2021, 12, 632335. [CrossRef] [PubMed]

59. Gurung, M.; Li, Z.; You, H.; Rodrigues, R.; Jump, D.B.; Morgun, A.; Shulzhenko, N. Role of gut microbiota in type 2 diabetes pathophysiology. EBioMedicine 2020, 51, 102590. [CrossRef]

60. Yang, G.; Wei, J.; Liu, P.; Zhang, Q.; Tian, Y.; Hou, G.; Meng, L.; Xin, Y.; Jiang, X. Role of the gut microbiota in type 2 diabetes and related diseases. Metabolism 2021, 117, 154712. [CrossRef] [PubMed]

61. Xu, Y.; Zhou, H.; Zhu, Q. The Impact of Microbiota-Gut-Brain Axis on Diabetic Cognition Impairment. Front. Aging Neurosci. 2017, 9, 106. [CrossRef] [PubMed]

62. Pruzin, J.J.; Nelson, P.T.; Abner, E.L.; Arvanitakis, Z. Review: Relationship of type 2 diabetes to human brain pathology. Neuropathol. Appl. Neurobiol. 2018, 44, 347-362. [CrossRef]

63. Biessels, G.J.; Despa, F. Cognitive decline and dementia in diabetes mellitus: Mechanisms and clinical implications. Nat. Rev. Endocrinol. 2018, 14, 591-604. [CrossRef]

64. Biessels, G.; Kappelle, L. Increased risk of Alzheimer's disease in Type II diabetes: Insulin resistance of the brain or insulin-induced amyloid pathology? Biochem. Soc. Trans. 2005, 33, 1041-1044. [CrossRef] [PubMed]

65. Roriz-Filho, J.S.; Sá-Roriz, T.M.; Rosset, I.; Camozzato, A.L.; Santos, A.C.; Chaves, M.L.; Moriguti, J.C.; Roriz-Cruz, M. (Pre)diabetes, brain aging, and cognition. Biochim. Biophys. Acta BBA Mol. Basis Dis. 2009, 1792, 432-443. [CrossRef] [PubMed]

66. Jacobson, A.M.; Samson, J.A.; Weinger, K.; Ryan, C.M. Diabetes, the brain, and behavior: Is there a biological mechanism underlying the association between diabetes and depression? Int. Rev. Neurobiol. 2002, 51, 455-479. [CrossRef] [PubMed]

67. Nouwen, A.; Nefs, G.; Caramlau, I.; Connock, M.; Winkley, K.; Lloyd, C.E.; Peyrot, M.; Pouwer, F.; European Depression in Diabetes (EDID) Research Consortium. Prevalence of Depression in Individuals With Impaired Glucose Metabolism or Undiagnosed Diabetes: A systematic review and meta-analysis of the European Depression in Diabetes (EDID) Research Consortium. Diabetes Care 2011, 34, 752-762. [CrossRef]

68. Breit, S.; Kupferberg, A.; Rogler, G.; Hasler, G. Vagus Nerve as Modulator of the Brain-Gut Axis in Psychiatric and Inflammatory Disorders. Front. Psychiatry 2018, 9, 44. [CrossRef]

69. Mergenthaler, P.; Lindauer, U.; Dienel, G.A.; Meisel, A. Sugar for the brain: The role of glucose in physiological and pathological brain function. Trends Neurosci. 2013, 36, 587-597. [CrossRef]

70. Utzschneider, K.M.; Kratz, M.; Damman, C.J.; Hullarg, M. Mechanisms Linking the Gut Microbiome and Glucose Metabolism. J. Clin. Endocrinol. Metab. 2016, 101, 1445-1454. [CrossRef] [PubMed]

71. Rodrigues, R.R.; Greer, R.L.; Dong, X.; Dsouza, K.N.; Gurung, M.; Wu, J.Y.; Morgun, A.; Shulzhenko, N. Antibiotic-Induced Alterations in Gut Microbiota Are Associated with Changes in Glucose Metabolism in Healthy Mice. Front. Microbiol. 2017, 8, 2306. [CrossRef]

72. Do, M.H.; Lee, E.; Oh, M.-J.; Kim, Y.; Park, H.-Y. High-Glucose or -Fructose Diet Cause Changes of the Gut Microbiota and Metabolic Disorders in Mice without Body Weight Change. Nutrients 2018, 10, 761. [CrossRef] 
73. Bonfili, L.; Cecarini, V.; Gogoi, O.; Berardi, S.; Scarpona, S.; Angeletti, M.; Rossi, G.; Eleuteri, A.M. Gut microbiota manipulation through probiotics oral administration restores glucose homeostasis in a mouse model of Alzheimer's disease. Neurobiol. Aging 2020, 87, 35-43. [CrossRef]

74. Davis, C.D. The Gut Microbiome and Its Role in Obesity. Nutr. Today 2016, 51, 167-174. [CrossRef] [PubMed]

75. Wu, S.-C.; Rau, C.-S.; Lu, T.-H.; Tzeng, S.-L.; Wu, Y.-C.; Wu, C.-J.; Lin, C.-W.; Hsieh, C.-H. Effect of Weight-Reduction in Obese Mice Lacking Toll-Like Receptor 5 and C57BL/6 Mice Fed a Low-Fat Diet. Mediat. Inflamm. 2015, 2015, 852126. [CrossRef] [PubMed]

76. Zietek, T.; Rath, E. Inflammation Meets Metabolic Disease: Gut Feeling Mediated by GLP-1. Front. Immunol. 2016, 7, 154. [CrossRef]

77. Larsen, N.; Vogensen, F.; Berg, F.V.D.; Nielsen, D.S.; Andreasen, A.S.; Pedersen, B.K.; Abu Al-Soud, W.; Sørensen, S.; Hansen, L.H.; Jakobsen, M. Gut Microbiota in Human Adults with Type 2 Diabetes Differs from Non-Diabetic Adults. PLoS ONE 2010, 5, e9085. [CrossRef]

78. Al-Jameel, S.S. Association of diabetes and microbiota: An update. Saudi J. Biol. Sci. 2021, 28, 4446-4454. [CrossRef] [PubMed]

79. Li, W.-Z.; Stirling, K.; Yang, J.-J.; Zhang, L. Gut microbiota and diabetes: From correlation to causality and mechanism. World J. Diabetes 2020, 11, 293-308. [CrossRef]

80. Zhang, J.; Ni, Y.; Qian, L.; Fang, Q.; Zheng, T.; Zhang, M.; Gao, Q.; Ni, J.; Hou, X.; Bao, Y.; et al. Decreased Abundance of Akkermansia muciniphila Leads to the Impairment of Insulin Secretion and Glucose Homeostasis in Lean Type 2 Diabetes. Adv. Sci. 2021, 8, 2100536. [CrossRef] [PubMed]

81. Zhou, K. Strategies to promote abundance of Akkermansia muciniphila, an emerging probiotics in the gut, evidence from dietary intervention studies. J. Funct. Foods 2017, 33, 194-201. [CrossRef] [PubMed]

82. Mazloom, K.; Siddiqi, I.; Covasa, M. Probiotics: How Effective Are They in the Fight against Obesity? Nutrients 2019, 11, 258. [CrossRef]

83. Cerdó, T.; García-Santos, J.A.; Bermúdez, M.G.; Campoy, C. The Role of Probiotics and Prebiotics in the Prevention and Treatment of Obesity. Nutrients 2019, 11, 635. [CrossRef] [PubMed]

84. Bartolomei, F.; Bonini, F.; Vidal, E.; Trébuchon, A.; Lagarde, S.; Lambert, I.; McGonigal, A.; Scavarda, D.; Carron, R.; Benar, C.G How does vagal nerve stimulation (VNS) change EEG brain functional connectivity? Epilepsy Res. 2016, 126, 141-146. [CrossRef]

85. Karakula-Juchnowicz, H.; Rog, J.; Juchnowicz, D.; Łoniewski, I.; Skonieczna-Żydecka, K.; Krukow, P.; Futyma-Jędrzejewska, M.; Kaczmarczyk, M. The study evaluating the effect of probiotic supplementation on the mental status, inflammation, and intestinal barrier in major depressive disorder patients using gluten-free or gluten-containing diet (SANGUT study): A 12-week, randomized, double-blind, and placebo-controlled clinical study protocol. Nutr. J. 2019, 18, 50. [CrossRef]

86. Peng, G.; Nourani, M.; Harvey, J.; Dave, H. Personalized Feature Selection for Wearable EEG Monitoring Platform. In Proceedings of the 2020 IEEE 20th International Conference on Bioinformatics and Bioengineering (BIBE), Cincinnati, OH, USA, 26-28 October 2020; pp. 380-386. [CrossRef]

87. Louis, E.K.S.; Frey, C.L.; Britton, W.J.; American Epilepsy Society. Electroencephalography (EEG): An Introductory Text and Atlas of Normal and Abnormal Findings in Adults, Children and Infants; American Epilepsy Society: Chicago, IL, USA, 2016. Available online: http:/ / www.ncbi.nlm.nih.gov/books/NBK390354/ (accessed on 5 November 2021).

88. Goldman, R.I.; Stern, J.M.; Engel, J.; Cohen, M.S. Simultaneous EEG and fMRI of the alpha rhythm. NeuroReport 2002, 13, 2487-2492. [CrossRef]

89. Mundy-Castle, A. Theta and beta rhythm in the electroencephalograms of normal adults. Electroencephalogr. Clin. Neurophysiol. 1951, 3, 477-486. [CrossRef]

90. Sachdev, R.N.S.; Gaspard, N.; Gerrard, J.; Hirsch, L.; Spencer, D.D.; Zaveri, H.P. Delta rhythm in wakefulness: Evidence from intracranial recordings in human beings. J. Neurophysiol. 2015, 114, 1248-1254. [CrossRef] [PubMed]

91. Miller, R. Theory of the normal waking EEG: From single neurones to waveforms in the alpha, beta and gamma frequency ranges. Int. J. Psychophysiol. 2007, 64, 18-23. [CrossRef] [PubMed]

92. Smailovic, U.; Koenig, T.; Savitcheva, I.; Chiotis, K.; Nordberg, A.; Blennow, K.; Winblad, B.; Jelic, V. Regional Disconnection in Alzheimer Dementia and Amyloid-Positive Mild Cognitive Impairment: Association Between EEG Functional Connectivity and Brain Glucose Metabolism. Brain Connect. 2020, 10, 555-565. [CrossRef]

93. Cui, D.; Liu, J.; Bian, Z.; Li, Q.; Wang, L.; Li, X. Cortical Source Multivariate EEG Synchronization Analysis on Amnestic Mild Cognitive Impairment in Type 2 Diabetes. Sci. World J. 2014, 2014, 523216. [CrossRef]

94. Cooray, G.; Nilsson, E.; Wahlin, Å.; Laukka, E.J.; Brismar, K.; Brismar, T. Effects of intensified metabolic control on CNS function in type 2 diabetes. Psychoneuroendocrinology 2011, 36, 77-86. [CrossRef]

95. Frøkjær, J.B.; Graversen, C.; Brock, C.; Khodayari-Rostamabad, A.; Olesen, S.S.; Hansen, T.; Søfteland, E.; Simrén, M.; Drewes, A. Integrity of central nervous function in diabetes mellitus assessed by resting state EEG frequency analysis and source localization. J. Diabetes Complicat. 2017, 31, 400-406. [CrossRef]

96. Benwell, C.S.; Davila-Pérez, P.; Fried, P.J.; Jones, R.N.; Travison, T.G.; Santarnecchi, E.; Pascual-Leone, A.; Shafi, M.M. EEG spectral power abnormalities and their relationship with cognitive dysfunction in patients with Alzheimer's disease and type 2 diabetes. Neurobiol. Aging 2020, 85, 83-95. [CrossRef]

97. Baskaran, A.; Milev, R.; McIntyre, R.S. A review of electroencephalographic changes in diabetes mellitus in relation to major depressive disorder. Neuropsychiatr. Dis. Treat. 2013, 9, 143-150. [CrossRef] 
98. Zeng, K.; Wang, Y.; Ouyang, G.; Bian, Z.; Wang, L.; Li, X. Complex network analysis of resting state EEG in amnestic mild cognitive impairment patients with type 2 diabetes. Front. Comput. Neurosci. 2015, 9, 133. [CrossRef]

99. Ebian, Z.; Eli, Q.; Ewang, L.; Elu, C.; Eyin, S.; Eli, X. Relative power and coherence of EEG series are related to amnestic mild cognitive impairment in diabetes. Front. Aging Neurosci. 2014, 6, 11. [CrossRef]

100. Lu, H.; Liu, J.; Gu, G.; Li, X.; Yin, S.; Cui, D. Nonlinear Phase Synchronization Analysis of EEG Signals in Amnesic Mild Cognitive Impairment with Type 2 Diabetes Mellitus. Neuroscience 2021, 472, 25-34. [CrossRef]

101. Bethiun, S.; Premaraja, R. Effect of Type 2 Diabetes Mellitus on Cognitive function and EEG in elderly patients. Int. J. Med. Sci. Clin. Inven. 2018, 5, 3678-3680. [CrossRef]

102. Panta, R.; Paudel, B.; Limbu, N. Electroencephalographic changes in type 2 diabetes mellitus during hyperventilation and post-hyperventilation. Int. J. Adv. Res. 2017, 5, 809-815. [CrossRef]

103. Pascal, V.; Pozuelo, M.; Borruel, N.; Casellas, F.; Campos, D.; Santiago, A.; Martinez, X.; Varela, E.; Sarrabayrouse, G.; Machiels, K.; et al. A microbial signature for Crohn's disease. Gut 2017, 66, 813-822. [CrossRef] [PubMed]

104. Zhang, X.; Zhang, D.; Jia, H.; Feng, Q.; Wang, D.; Liang, D.; Wu, X.; Li, J.; Tang, L.; Li, Y.; et al. The oral and gut microbiomes are perturbed in rheumatoid arthritis and partly normalized after treatment. Nat. Med. 2015, 21, 895-905. [CrossRef] [PubMed]

105. Karlsson, F.; Fåk, F.; Nookaew, I.; Tremaroli, V.; Fagerberg, B.; Petranovic, D.; Bäckhed, F.; Nielsen, J. Symptomatic atherosclerosis is associated with an altered gut metagenome. Nat. Commun. 2012, 3, 1245. [CrossRef] [PubMed]

106. Glassner, K.L.; Abraham, B.P.; Quigley, E.M. The microbiome and inflammatory bowel disease. J. Allergy Clin. Immunol. 2020, 145, 16-27. [CrossRef] [PubMed] 